\title{
Evidence for an association between mannose-binding lectin 2 (MBL2) gene polymorphisms and pre-term birth
}

Olaf A. Bodamer, $M D^{1}$, Georg Mitterer, $P h D^{2}$, Wolfgang Maurer, $M D^{1}$, Arnold Pollak, $M D^{3}$, Manfred W. Mueller, $P h D^{2}$, and Wolfgang M. Schmidt, $P h D^{4}$

\begin{abstract}
Purpose: Human mannose-binding lectin, encoded by the MBL2 gene, is an important component of innate immunity and an important regulator of inflammatory processes. MBL2 gene polymorphisms are associated with an increased risk of neonatal infections and some data suggest a relation between the maternal MBL2 genotype and the risk of premature delivery. In this study, we evaluated whether there is an association between the fetal MBL2 genotype and prematurity. Methods: A microarray-based on-chip PCR method was used to simultaneously detect five common MBL2 polymorphisms (codon 52, 54, 57; promoter -550, -221) in 204 DNA samples isolated from archival blood cards. MBL2 genotypes of infants born before the $36^{\text {th }}$ week of pregnancy $(N=102)$ were compared to a control group of infants born at term after the $37^{\text {th }}$ week $(N=102)$. Results: The frequency of the codon 52 polymorphism was significantly higher in the pre-term group compared to the term group $(10.8 \%$ versus $4.9 \%, P=0.04)$, while the frequency of the codon 54 polymorphism was equal in both groups $(11.3 \%$ versus $11.8 \%)$. Interestingly, carriers of genotypes $(0 / 0)$ likely conferring deficient MBL plasma levels were more common in the group of premature birth $(9.8 \%$ versus $2.9 \%, P=0.05)$, while the promoter $-550 \mathrm{C} / \mathrm{C}$ genotype was underrepresented in the pre-term birth group (24.5\% versus $39.2 \%, P=0.03)$. Conclusion: Our data add to the knowledge about genetic predisposition to prematurity and suggest that the fetal MBL2 genotype might be an additional genetic factor contributing to the risk of premature delivery. Genet Med 2006:8(8):518-524.
\end{abstract}

Key Words: Polymorphism, mannose-binding lectin, pre-term, microarray, association

Pre-term delivery is the worldwide leading cause of infant mortality and morbidity. In the United States of America between 7 and $8 \%$ of live-born newborn infants are born with a birth weight of 2,500 g or less every year. ${ }^{1}$ About $20 \%$ of these weigh $1,500 \mathrm{~g}$ or less and are mostly born prematurely. The causes for premature birth and intrauterine growth retardation are closely related and are multifactorial in origin; many social, environmental, medical and genetic factors have been suggested. ${ }^{1-3}$ Genetic contributions from both mother and fetus probably play a role in determining gestational length and could confer a possible genetic predisposition toward pre-term birth. ${ }^{4}$ Among identifiable causes of pre-term birth, infections seem to be the most prevalent and it is therefore conceivable

From the ${ }^{1}$ Department of General Pediatrics, University Children's Hospital, Medical University of Vienna, 1090 Vienna, Austria; ${ }^{2}$ VBC-Genomics Bioscience Research, 1030 Vienna, Austria: ${ }^{3}$ Department of Neonatology and Intensive Care, University Children's Hospital, Medical University of Vienna, 1090 Vienna, Austria; and the ${ }^{4}$ Department of Clinical Pharmacology, Medical University of Vienna, 1090 Vienna, Austria.

Professor Olaf Bodamer, MD, FACMG, Dr. Wolfgang Schmidt, Center for Inborn Errors and Pediatric Genetics, Department of General Pediatrics, Department of Clinical Pharmacology, Medical University of Vienna, Waehringer Guertel 18-20, A-1090 Vienna, Austria.

Submitted for publication March 28, 2006.

Accepted for publication May 26, 2006.

DOI: 10.1097/01.gim.0000232478.43335.19 that genetic factors that predispose to infections may play an important role. ${ }^{5}$ A candidate gene study focusing on genes that encode cytokines, mediators of apoptosis and of host defense found associations with allelic variants in the genes for interleukin 4 and 10 (IL4, IL10), the tumor necrosis factor alpha (TNF- $\alpha$ ), and the mannose-binding lectin gene (MBL2). ${ }^{6}$ The possible genetic context between infection, inflammation and pre-term delivery is also supported by other findings, in particular for the IL4 and TNF- $\alpha$ genes. ${ }^{7-9}$ The human mannosebinding lectin (MBL) is an important component of the body's first line immune response. MBL deficiency has been repeatedly associated with an increased susceptibility for a wide variety of infections. The above-mentioned study by Annells et al. has indicated a possible causal relationship between a genetic variant in the human gene encoding MBL (MBL2) and the risk of pre-term birth. ${ }^{6}$ Previously, low MBL serum levels were found to be associated with an increased risk of unexplained recurrent miscarriage. ${ }^{10-12}$ An association with $M B L 2$ variant genotypes was observed in a genotyping study, ${ }^{13}$ whereas another study, however, did not ascertain any MBL2 genotype differences between groups of women with recurrent miscarriages and those without. ${ }^{14}$

The proper function of MBL, an acute-phase protein of the liver, is essential for opsonisation of a multitude of different 
bacteria and yeast. MBL is particularly important for innate immunity, especially during the natural hypogammaglobulinemic phase, ${ }^{15-17}$ but has also been associated with unusual and severe infections during adulthood, with autoimmune disorders, or acute lymphoblastic leukemia of childhood. ${ }^{18-22} \mathrm{Ge}$ netically, MBL deficiency and low levels of serum MBL are associated with the presence of non-synonymous polymorphisms within the coding region and the promoter region of the MBL2 gene. ${ }^{23}$ The structural variants affect exon 1 of the $M B L 2$ gene and are generally believed to interfere with oligomerization of the protein. In addition, two polymorphisms in the promoter region building haplotypes associated with low MBL serum levels have been described. ${ }^{24}$

In this study, we analyzed these five polymorphic changes in the MBL2 coding and promoter region in a group of infants born prematurely and compared their genotype with a control group of infants born at term in order to identify a possible relationship between the risk of premature birth and the fetal $M B L 2$ genotype.

\section{METHODS}

\section{Study subjects and DNA extraction}

A total of 204 archival dried blood filter cards have been randomly selected from infants born prematurely $(\mathrm{N}=102)$ and from infants born at term $(\mathrm{N}=102)$. Prematurity was defined as birth prior to the $36^{\text {th }}$ week of pregnancy as opposed to term birth after the $37^{\text {th }}$ week as recorded on the cards. The filter cards have been obtained from the Austrian Newborn Screening Program. The study was approved by the Ethics Committee of the Medical University of Vienna (No. 300/2002). Genomic DNA was extracted from $3 \mathrm{~mm}$ diameter punches prepared from the blood spots on the Guthrie cards using the MasterPure Complete DNA and RNA Purification Kit (Epicenter Technologies, Madison, WI).

\section{MBL2 SNPs and PCR primers}

For the amplification of genomic fragments encompassing the five MBL2 polymorphisms of interest, we used PCR primer sets for the synchronous, multiplex amplification of three fragments of the MBL2 gene. One fragment spanned a part of exon 1 containing codon 52 (variant D, CGT>TGT, Arg52Cys), codon 54 (variant B, GGC> GAC, Gly54Asp) and codon 57 (variant C, GGA $>$ GAA, Gly57Glu), and two other fragments contained either nucleotide position -221 (variant $\mathrm{Y}, \mathrm{G} / \mathrm{C}$ ) or nucleotide position -550 (variant L, C/G) of the MBL2 promoter region. All nucleotide variants studied herein are labeled according to the international nomenclature, have been first described by others and are referenced in the Human Gene Mutation Database with the following accession numbers: CM960957, CM920484, CM920485, CR952185, CR952186. ${ }^{24-29}$ The primers were designed using MBL2 gene genomic sequence (GenBank accession number AL731550) and employing the Primer3 algorithm for primer sequence selection. ${ }^{30}$ The primers amplified PCR fragments of 156-157 bp, had a melting temperature of $65-66^{\circ} \mathrm{C}$ and were checked for potential mispriming in known
MBL2 pseudogene sequences. The multiplex PCR system as well as quantity and integrity of extracted DNA were verified by conventional PCR amplifications and analysis of PCR products using the DNA 1000 LabChip kit on an Agilent 2100 Bioanalyzer (Agilent Technologies, Palo Alto, CA). Primer sequences have been described in detail elsewhere. ${ }^{31}$

\section{Genotyping by on-chip PCR}

For the genotyping we used a previously described DNA microarray-based amplification protocol (on-chip PCR), allowing the amplification and simultaneous characterization of a DNA sample for the identification of SNPs. ${ }^{32,33}$ In brief, on-chip PCR is performed on the top of a glass chip with covalently bound, microarrayed allele-specific nested PCR primers. PCR products generated in the liquid phase are re-amplified in a semi-nested PCR directly on the chip surface. Reaction products are visualized by the incorporation of a biotin-labeled nucleotide that can be used for fluorescence detection using conventional streptavidindye conjugate chemistry.

Preparation of the slides, spotting, and covalent coupling of the solid-phase, allele-specific nested PCR primers was done exactly as described previously. ${ }^{31,33}$ The oligonucleotide microarray comprised of a set of three different allele-specific primer pairs for each SNP and four identical replicate arrays. On-chip PCR was carried out in a $13 \mu \mathrm{l}$ PCR reaction mix containing $2 \times$ HotStar Taq PCR-buffer, $100 \mu \mathrm{M}$ of dATP, dGTP, dCTP, $65 \mu \mathrm{M}$ dTTP (Amersham Biosciences Europe, Freiburg, Germany) and $35 \mu \mathrm{M}$ Biotin-16-dUTP (Roche Diagnostics, Mannheim, Germany), 1 U HotStar Taq DNA Polymerase (Qiagen, Hilden, Germany), $1.4 \mu \mathrm{M}$ of each liquidphase primers, and the genomic DNA sample $(\sim 20 \mu \mathrm{g})$. Reaction additives necessary for on-chip PCR were BSA $(0.25$ $\mu \mathrm{g} / \mu \mathrm{l})$ and Self-Seal Reagent (25\%; MJ Research, Waltham, MA), The PCR was carried out in a PTC 200 In Situ Slide Cycler (MJ Research) using the following cycling scheme: $80^{\circ} \mathrm{C}$ for 10 minutes, $95^{\circ} \mathrm{C}$ for 5 minutes, 10 cycles at $95^{\circ} \mathrm{C}$ for 30 seconds, $66^{\circ} \mathrm{C}$ for 25 seconds and $72^{\circ} \mathrm{C}$ for 35 seconds, followed by 25 cycles at $95^{\circ} \mathrm{C}$ for 20 seconds, $66^{\circ} \mathrm{C}$ for 10 seconds and $72^{\circ} \mathrm{C}$ for 20 seconds with a final extension step of 3 minutes at $72^{\circ} \mathrm{C}$. After PCR, the slides were washed and stained with Alexa Fluor 647-labeled Streptavidin (Molecular Probes, Eugene, OR). The slides were scanned using an Affymetrix 428 Scanner (Affymetrix, Santa Clara, CA) and the images were analyzed using a custom developed software for spot finding, fluorescence intensity (FI) extraction and automated genotype assignment ( $\mu$ IA, Microarray Image Analyzer, VBC-Genomics Bioscience Research, Vienna, Austria). The whole procedure has been validated, compared to standard DNA sequencing and published elsewhere. ${ }^{31}$ The method successfully assigned a genotype in $\mathrm{N}=$ 102 samples in each group.

\section{Statistical analysis and haplotype assignment}

Depending on the absence or presence of particular genotypes or haplotypes, we calculated standard measures for the odds ratios $(\mathrm{OR})$ and the standard error of $\log (\mathrm{OR})$, tested the significance of $\log (\mathrm{OR})$ and constructed confidence limits 
(two-sided 95\% confidence intervals, CI). We determined $P$ values by assessing the distribution of the standard normal curve for no association of genotype with pre-term birth. The uncorrected probability value of 0.05 was considered significant. In addition to the calculation of odds ratios, Pearson $\chi^{2}$ tests of association were performed, for which we used the VassarStats web interface for statistical computing (http://faculty.vassar.edu/ lowry/VassarStats.html). Chi square analysis was performed for those genotypes as defined below that were shared by at least 10 individuals.

In addition to the SNP analysis, we deduced the haplotypes from the three exon 1 genotypes (either all wild-type (A), or "O," for either the codon 52 Cys variant, "D," or the codon 54 Asp variant, "B," or the codon 57 Glu variant, "C") together with the two promoter SNP genotypes, -221 (G>C; "Y" or "X") and -550 (C>G; "H" or "L"). Thus, we were able to assign six commonly found haplotypes (HYA, LYA, LXA, HYD, LYB, LYC) and could consider 2 (HXA and HYB) of 4 rare haplotypes (LXB and LYD, not considered) that have been occasionally reported. ${ }^{23}$ Because we did not measure the SNP in the $5^{\prime}$ untranslated sequence at position $+4(\mathrm{P} / \mathrm{Q})$, we were not able to discriminate between the common LYPA and LYQA haplotypes. ${ }^{23,24}$

\section{RESULTS}

To explore a possible association between the risk of premature birth and the fetal MBL2 genotype, we genotyped 5 common polymorphisms within the MBL2 gene among 204 individual newborns. We evaluated nonsynonymous polymorphisms within exon 1 causing structural variants (codons 52, 54, and 57) associated with MBL deficiency as well as allelic variants in the promoter region conferring low MBL levels. The results of the genotyping study are summarized in Table 1. The genotypes of 102 infants with a pre-term birth at $<36$ weeks of pregnancy were compared with a control group of 102 term-born infants. The mean birth weight $(95 \% \mathrm{CI})$ at birth was $2,473 \mathrm{~g}( \pm 111)$ in the pre-term birth group and 3,537 $\mathrm{g}$ $( \pm 80)$ in the control group, with $54 \%$ girls in the pre-term group and $47 \%$ in the control group (Table 2). Heterozygous and homozygous carriers of the codon 52 variant (D-allele, Arg52Cys) genotype were significantly more frequent in the pre-term group (20.6 versus $9.8 \%, \mathrm{OR}=2.39$, CI $1.06-5.36$, $P=0.04$ ) (Table 2). Also, the D-allele frequency was significantly higher in the pre-term group compared to the term group (10.8 versus $4.9 \%$; $\mathrm{OR}=2.35$, CI 1.08 $-5.09, P=0.03$ ), while the frequency of the codon 54 SNP (B-allele, Gly54Asp) was not different (11.3 versus $11.8 \%)$. Carriers of the rare codon 57 polymorphism (C-allele, Gly57Glu) were more prevalent in the pre-term group (3.9 versus 2.0\%). Though conspicuous, statistical significance was not reached for the latter association. We then assigned haplotypes to the five SNP genotypes in each sample and tested for differential frequencies between both groups (Table 2). While the HYD haplotype was significantly overrepresented $(P=0.03)$, as expected from the first observed higher D-allele frequency, the LYA haplotype was underrepresented in the pre-term birth group $(24.5 \%$ versus $34.8 \%$; OR $=0.61$; CI $0.40-0.93, P=0.03$ ). No difference was observed for the HYA, LXA, and LYB haplotypes, while the rare LYC, HYB, and HXA haplotypes seemed to be more frequent in the pre-term birth group. Next, we sought to derive MBL genotypes based on the haplotype analysis. The corresponding genotype results are summarized graphically in Figure 1. The underrepresentation of the LYA haplotype was readily explained by the fact that carriers of the homozygous LYA/LYA genotype were significantly more frequent in the control group when compared to the pre-term birth group ( 15.7 versus $3.9 \%$; $\mathrm{OR}=0.22$; $\mathrm{CI}=$ $0.07-0.68, P=0.01$, not shown). The genotype analysis further revealed that carriers of the HYA/HYD genotype (3.9 versus $0 \%$ ), of the compound heterozygous LYB/HYD genotype (4.9 versus $1.0 \%$ ), the LXA/LXA genotype (2.9 versus $0 \%$ ), and of rare heterozygous genotypes (LXA/LYC, HXA/O) were - although without significance - more common in the pre-term birth group. In

Table 1

$M B L 2$ genotype data

\begin{tabular}{|c|c|c|c|c|c|c|c|c|c|c|}
\hline \multirow[b]{2}{*}{$\mathrm{SNP} A>\mathrm{a}$} & \multicolumn{2}{|c|}{$\begin{array}{c}\text { Promoter }-550[\mathrm{H} / \mathrm{L}] \\
\mathrm{C}>\mathrm{G} \\
\end{array}$} & \multicolumn{2}{|c|}{$\begin{array}{c}\text { Promoter -221 [Y/X] } \\
\mathrm{G}>\mathrm{C} \\
\end{array}$} & \multicolumn{2}{|c|}{$\begin{array}{c}\text { Codon } 52[\mathrm{~A} / \mathrm{D}] \\
\mathrm{C}>\mathrm{T} \\
\end{array}$} & \multicolumn{2}{|c|}{$\begin{array}{c}\text { Codon } 54[\mathrm{~A} / \mathrm{B}] \\
\mathrm{G}>\mathrm{A}\end{array}$} & \multicolumn{2}{|c|}{$\begin{array}{c}\text { Codon } 57[\mathrm{~A} / \mathrm{C}] \\
\mathrm{G}>\mathrm{A} \\
\end{array}$} \\
\hline & Control & Pre-term & Control & Pre-term & Control & Pre-term & Control & Pre-term & Control & Pre-term \\
\hline \multicolumn{11}{|l|}{ Genotype } \\
\hline $\mathrm{A} / \mathrm{A}$ & 40 & 25 & 67 & 66 & 92 & 81 & 80 & 81 & 100 & 98 \\
\hline $\mathrm{A} / \mathrm{a}$ & 52 & 63 & 35 & 33 & 10 & 20 & 20 & 18 & 2 & 4 \\
\hline $\mathrm{a} / \mathrm{a}$ & 10 & 14 & 0 & 3 & 0 & 1 & 2 & 3 & 0 & 0 \\
\hline \multicolumn{11}{|l|}{ Test for HWE } \\
\hline Deviation & 0.24 & 0.01 & 0.04 & 0.64 & 0.60 & 0.85 & 0.57 & 0.13 & 0.92 & 0.84 \\
\hline \multicolumn{11}{|c|}{ Tests for association } \\
\hline A/a carriers & \multicolumn{2}{|c|}{0.04} & \multicolumn{2}{|c|}{0.88} & \multicolumn{2}{|c|}{0.05} & \multicolumn{2}{|c|}{0.74} & \multicolumn{2}{|r|}{0.41} \\
\hline $\begin{array}{l}\text { Minor allele } \\
\text { positivity }\end{array}$ & \multicolumn{2}{|c|}{0.02} & \multicolumn{2}{|c|}{0.88} & \multicolumn{2}{|r|}{0.03} & \multicolumn{2}{|c|}{0.86} & \multicolumn{2}{|r|}{0.41} \\
\hline
\end{tabular}


Table 2

$M B L 2$ allele variants and pre-term birth

\begin{tabular}{|c|c|c|c|c|}
\hline & Controls $(\mathrm{N}=102)$ & Pre-term birth $(\mathrm{N}=102)$ & Odds ratio (CI 95\%) & $\mathrm{P}\left[\chi^{2}\right.$ (Pearson) $]$ \\
\hline \multicolumn{5}{|c|}{ General characteristics of infants } \\
\hline Week of pregnancy & $>37$ & $<36$ & & \\
\hline Sex, female & $48(47.1 \%)$ & $55(53.9 \%)$ & & \\
\hline Birth weight [CI 95\%, (SD)] & $3,537 \mathrm{~g}[3,457-3,617,(414)]$ & $2,473 \mathrm{~g}[2,362-2,584,(568)]$ & & \\
\hline \multicolumn{5}{|l|}{ MBL2 exon 1 variant carriers } \\
\hline Gly54Asp, B-allele & $22(21.6 \%)$ & $21(20.6 \%)$ & & \\
\hline Gly57Glu, C-allele & $2(2.0 \%)$ & $4(3.9 \%)$ & & \\
\hline Arg52Cys, D-allele & $10(9.8 \%)$ & $21(20.6 \%)$ & $2.39(1.06-5.36)$ & 0.03 \\
\hline \multicolumn{5}{|l|}{ MBL2 haplotype distribution } \\
\hline HYA & $62(30.4 \%)$ & $65(31.9 \%)$ & & \\
\hline LYA & $71(34.8 \%)$ & $50(24.5 \%)$ & $0.61(0.40-0.93)$ & 0.02 \\
\hline LXA & $35(17.2 \%)$ & $36(17.6 \%)$ & & \\
\hline HYD & $10(4.9 \%)$ & $22(10.8 \%)$ & $2.35(1.08-5.09)$ & 0.03 \\
\hline LYB & $24(11.8 \%)$ & $23(11.3 \%)$ & & \\
\hline LYC & $2(1.0 \%)$ & $4(2.0 \%)$ & & \\
\hline Rare (HXA, HYB) & $0(0.0 \%)$ & $4(2.0 \%)$ & & \\
\hline \multicolumn{5}{|c|}{ MBL2 genotype and phenotype classes } \\
\hline YA/YA & $41(40.2 \%)$ & $36(35.3 \%)$ & & \\
\hline YA/XA & $28(27.5 \%)$ & $23(22.5 \%)$ & & \\
\hline XA/XA & $0(0.0 \%)$ & $3(2.9 \%)$ & & \\
\hline Sum A/A & $69(67.6 \%)$ & $62(60.8 \%)$ & & \\
\hline YA/B & $15(14.7 \%)$ & $8(7.8 \%)$ & & \\
\hline $\mathrm{XA} / \mathrm{B}$ & $4(3.9 \%)$ & $4(3.9 \%)$ & & \\
\hline Sum A/B & $19(18.6 \%)$ & $12(11.8 \%)$ & & \\
\hline YA/C & $2(2.0 \%)$ & $1(1.0 \%)$ & & \\
\hline $\mathrm{XA} / \mathrm{C}$ & $0(0.0 \%)$ & $3(2.9 \%)$ & & \\
\hline Sum A/C & $2(2.0 \%)$ & $4(3.9 \%)$ & & \\
\hline YA/D & $6(5.9 \%)$ & $11(10.8 \%)$ & & \\
\hline $\mathrm{XA} / \mathrm{D}$ & $3(2.9 \%)$ & $3(2.9 \%)$ & & \\
\hline Sum A/D & $9(8.8 \%)$ & $14(13.7 \%)$ & & \\
\hline YA/O & $23(22.5 \%)$ & $20(19.6 \%)$ & & \\
\hline $\mathrm{XA} / \mathrm{O}$ & 7 (6.9\%) & $10(9.8 \%)$ & & \\
\hline Sum A/O & $30(29.4 \%)$ & $30(29.4 \%)$ & & \\
\hline $\mathrm{B} / \mathrm{B}$ & $2(2.0 \%)$ & $3(2.9 \%)$ & & \\
\hline $\mathrm{D} / \mathrm{D}$ & $0(0.0 \%)$ & $1(1.0 \%)$ & & \\
\hline $\mathrm{B} / \mathrm{D}$ & $1(1.0 \%)$ & $6(5.9 \%)$ & & \\
\hline Sum $\mathrm{O} / \mathrm{O}$ & $3(2.9 \%)$ & $10(9.8 \%)$ & $3.59(0.96-13.4)$ & 0.05 \\
\hline
\end{tabular}

the last step, we assessed possible associations with low MBL producing genotypes. We assigned a putatively "insufficient MBL" phenotype to the group of $\mathrm{O} / \mathrm{O}$ genotypes. As can be seen in Table 2 , carriers of $\mathrm{O} / \mathrm{O}$ genotypes, mainly represented by compound heterozygotes, were more common in the pre-term birth group (also confer Fig. 1).

In order to study effects of birth weight within the pre-term subgroup we have performed a binned analysis based on birth 


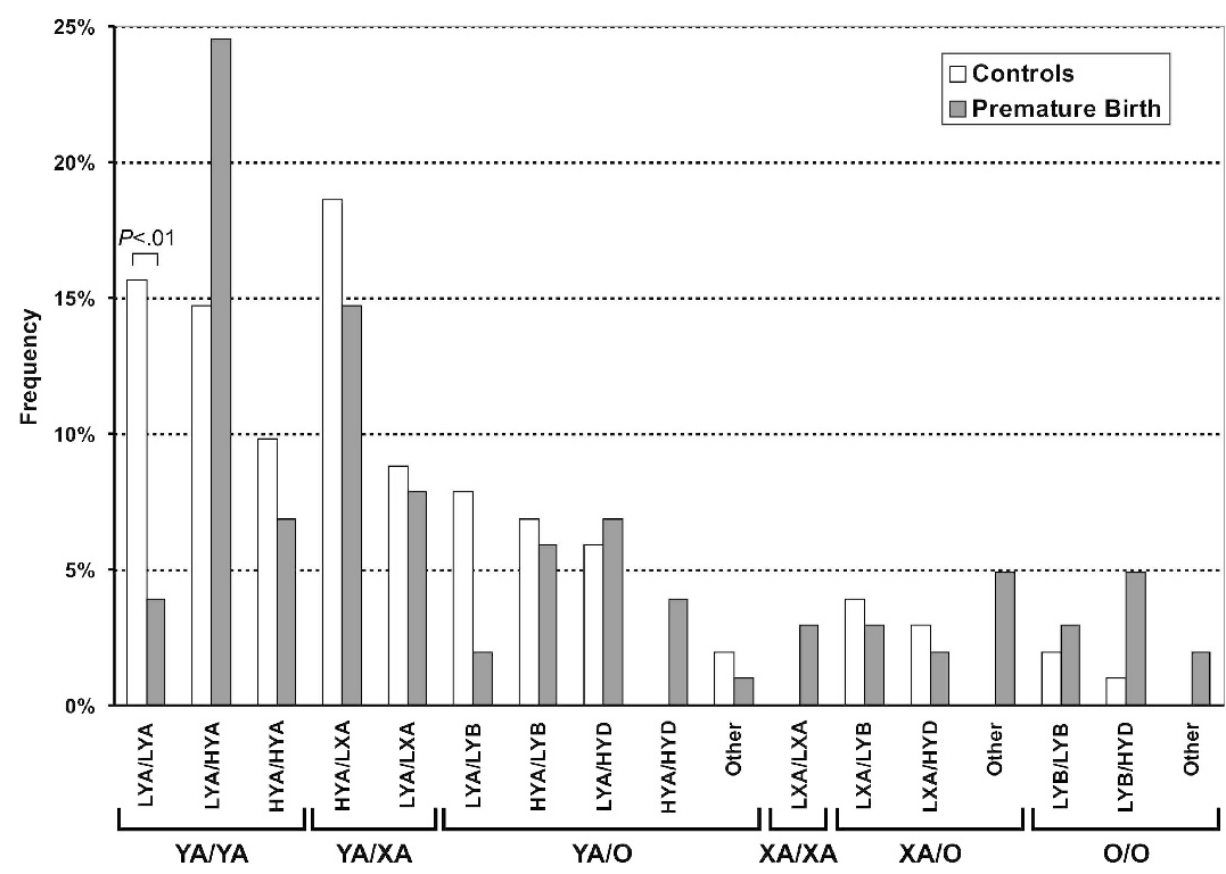

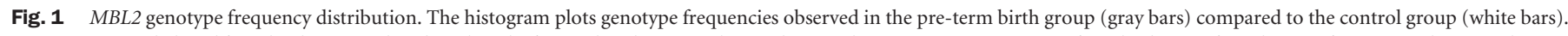

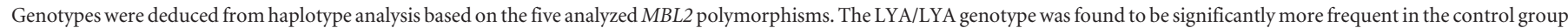

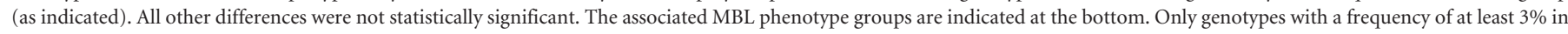
one group (indicated on the horizontal axis) were considered for graphical representation (residual genotypes are subsumed in "other").

weight, which showed that $8 / 10$ carriers of an $\mathrm{O} / \mathrm{O}$ genotype were within the 2,480-3,120 g range. This finding indicates that MBL deficient genotypes may not be correlated with the earliest pre-term deliveries.

Generally, carriers of low MBL concentration-conferring genotypes $(\mathrm{O} / \mathrm{O}$ and $\mathrm{XA} / \mathrm{O})$ were more frequent in the prematurity group (19.6 versus $9.8 \%, P=0.05$ ).

\section{DISCUSSION}

Premature delivery and pre-term birth carries a significant medical and socio-economic burden for the affected families and societies as a whole. ${ }^{3} \mathrm{~A}$ causal relationship between intrapartal infections and an increased risk of premature birth has been well documented in many studies. ${ }^{5}$ Maternal genetic predisposition to infections is therefore likely to play a role in premature birth but it is unknown whether fetal genetic predisposition may contribute to this risk as well. Consequently we examined fetal MBL2 genotypes in a group of premature infants and compared them to a group of infants born at term. We found a significant overrepresentation of carriers of the codon 52 variant (D-allele, Arg52Cys) in a group of infants born before week 36 of pregnancy when compared to infants born at term. This is the first study to show a possible connection between fetal variant $M B L 2$ genotypes and the risk of prematurity. This finding has several interesting consequences. Provided that the observed genetic association reflects a functional coherence, our finding could suggest that MBL plays a role in the innate immunity of the unborn child. In this context it is noteworthy that the human MBL2 gene is expressed in fetal liver as demonstrated in a large-scale analysis of the human transcriptome. ${ }^{34}$ Fetal mannose-binding protein produced by the fetal liver might play a role in the defense of pathogens and/or modulation of immune response during gestation, providing a functional basis for the observed association with preterm birth. This would also suggest differences between the biochemical phenotypes of the structural variants, based on the fact that we did not find such an association with the codon 54 (B-allele, Gly54Asp) variant.

Variants B, D, C are 3 different variant alleles that have evolved separately during human history, which has been demonstrated by Madsen and coworker. ${ }^{27}$ This view is also supported by SNP databases linked to the human genome reference sequence and has been further supported recently by a comprehensive MBL2 haplotype study. ${ }^{35}$

Our haplotyping results revealed that LYB/HYD (i.e., the compound heterozygotes) and HYA/HYD genotype carriers were over-represented in the pre-term birth group, while the LYA/HYD and LXA/HYD genotypes were not. With the exception of the compound heterozygous genotype that is normally causing an MBL deficient phenotype, this seems to be paradox, because the LXA/HYD genotype is generally associated with lower MBL levels than the HYA/HYD genotype. ${ }^{23}$ This would suggest a hitherto unknown, functional difference of the biochemical phenotypes between the three structural MBL variants and probably involve some MBL level independent particular traits for the $\mathrm{D}$ variant.

Due to the small sample size in our study, we sought to investigate if genotyping data may be summarized by functional phenotype categories based on known relationships be- 
tween MBL2 variants and MBL serum levels published previously by others. ${ }^{15,23}$ Carrier counts of genotypes most likely conferring deficient $\mathrm{MBL}$ levels $(\mathrm{O} / \mathrm{O})$ were significantly higher in the pre-term birth group (Table 2). On the other hand, we noticed a remarkable, statistically significant, underrepresentation of LYA/LYA genotype (promoter $-550 \mathrm{C} / \mathrm{C}$ ) carriers in the pre-term birth group. It is important to note that the LYA haplotype frequency observed in the control group (35\%) was higher when compared to LYA frequencies in European populations reported by others, e.g., for the Czech population (27\%). ${ }^{36}$ This finding could suggest that this particular fetal MBL2 genotype might be "protective." Interestingly, the LYA/LYA genotype was recently reported to be negatively associated with Behcet's disease, while the HYA haplotype contributed to the occurrence of this inflammatory disease. ${ }^{37}$ This could suggest different, structure variant-independent, functional roles for the LYA and HYA promoter haplotypes with regard to susceptibility to inflammatory disease. Also, the possibility that the LYA haplotype is linked to another functional genetic polymorphism in vicinity to the MBL2 gene cannot be ruled out. This speculation is also supported by a recent report revealing a high degree of heterozygosity across the MBL2 gene but a restricted number of haplotypes some of which might extend to neighboring genes which encode the two surfactant proteins $S P-A$ and $S P-D .{ }^{35}$ Our study adds to the present knowledge about possible genetic factors involved in infection and pre-term delivery. Because MBL is an important component of host defense, a connection with infections and preterm birth is obvious. Indeed, the recent study by Annells et al. has indicated a first, possible causal relationship between a genetic variant in the MBL2 gene and the risk of pre-term birth. ${ }^{6}$ Interestingly, these authors demonstrated odds for the Asp54 variant, which was equally distributed in both groups in our study of fetal genotypes. Although the results cannot be readily compared because maternal genotypes have not been ascertained in our study, together these data support the connection between MBL and pre-term birth. Before, low MBL serum levels were found to be associated with an increased risk of unexplained recurrent miscarriage. ${ }^{10-12}$ An association with low MBL level conferring MBL2 variant genotypes was reported in a genotyping study, ${ }^{13}$ whereas another study conducted by another group did not ascertain any $M B L 2$ genotype differences between groups of women with recurrent miscarriages and those without. ${ }^{14}$

Our study has important limitations that require consideration. First, a larger study sample size is needed for defining a definitive, statistically powerful association between MBL2 genotype and the risk of pre-term birth. Second, elucidation of the exact role of the fetal genotype would require knowledge of parental genotypes. Third, we cannot completely exclude the possibility that our study is confounded by an ethnical bias because the archival blood cards where randomly selected, based solely on the week of pregnancy at birth. Despite these limitations, our study adds to the rare knowledge about the possible genetic contributions from the fetus in determining gestational length and suggests a complex role of MBL and inflammation. Our finding that the relatively common codon 52 variant could possibly confer a fetal genetic predisposition toward pre-term birth merits further investigation in a larger, prospective study.

\section{ACKNOWLEDGMENTS}

The authors thank Prof. Dr. Barbara Schneider (Department of Medical Statistics, Medical University of Vienna) for helpful advice on statistical analysis.

\section{References}

1. Stoll B, Kliegman R. The high-risk infant. In: Behrman RE, Kliegman RM, Jenson HB, editors. The Nelson textbook of pediatrics. Philadelphia: Saunders, 2004;547559.

2. Hoffman JD, Ward K. Genetic factors in pre-term delivery. Obstet Gynecol Surv 1999;54:203-210.

3. Ward K. Genetic factors in pre-term birth. BJOG 2003;110 Suppl 20:117.

4. Adams KM, Eschenbach DA. The genetic contribution towards pre-term delivery. Semin Fetal Neonatal Med 2004;9:445-452.

5. Romero R, Espinoza J, Chaiworapongsa T, Kalache K, et al. Infection and prematurity and the role of preventive strategies. Semin Neonatol 2002;7:259-274.

6. Annells MF, Hart PH, Mullighan CG, Heatley SL, et al. Interleukins-1, -4, -6, -10, tumor necrosis factor, transforming growth factor-beta, FAS, and mannose-binding protein C gene polymorphisms in Australian women: Risk of pre-term birth. Am J Obstet Gynecol 2004;191:2056-2067.

7. Kalish RB, Vardhana S, Gupta M, Perni SC, et al. Interleukin-4 and - 10 gene polymorphisms and spontaneous pre-term birth in multifetal gestations. Am J Obstet Gynecol 2004;190:702-706.

8. Macones GA, Parry S, Elkousy M, Clothier B, et al. A polymorphism in the promoter region of TNF and bacterial vaginosis: preliminary evidence of gene-environment interaction in the etiology of spontaneous pre-term birth. Am J Obstet Gynecol 2004;190:1504-1508.

9. Moore S, Ide M, Randhawa M, Walker JJ, et al. An investigation into the association among pre-term birth, cytokine gene polymorphisms and periodontal disease. BJOG 2004;111:125-132.

10. Kilpatrick DC, Bevan BH, Liston WA. Association between mannan binding protein deficiency and recurrent miscarriage. Hum Reprod 1995;10:2501-2505.

11. Christiansen OB, Kilpatrick DC, Souter V, Varming K, et al. Mannan-binding lectin deficiency is associated with unexplained recurrent miscarriage. Scand J Immunol 1999;49:193-196.

12. Kilpatrick DC, Starrs L, Moore S, Souter V, et al. Mannan binding lectin concentration and risk of miscarriage. Hum Reprod 1999;14:2379-2380.

13. Kruse C, Rosgaard A, Steffensen R, Varming K, et al. Low serum level of mannanbinding lectin is a determinant for pregnancy outcome in women with recurrent spontaneous abortion. Am J Obstet Gynecol 2002;187:1313-1320.

14. Baxter N, Sumiya M, Cheng S, Erlich H, et al. Recurrent miscarriage and variant alleles of mannose binding lectin, tumour necrosis factor and lymphotoxin alpha genes. Clin Exp Immunol 2001;126:529-534.

15. Kilpatrick DC. Mannan-binding lectin: clinical significance and applications. Biochim Biophys Acta 2002;1572:401-413.

16. Eisen DP, Minchinton RM. Impact of mannose-binding lectin on susceptibility to infectious diseases. Clin Infect Dis 2003;37:1496-1505.

17. Turner MW. The role of mannose-binding lectin in health and disease. Mol Immunol 2003;40:423-429.

18. Summerfield JA, Ryder S, Sumiya M, Thursz M, et al. Mannose binding protein gene mutations associated with unusual and severe infections in adults. Lancet 1995;345: 886-889.

19. Garred P, Madsen HO, Halberg P, Petersen J, et al. Mannose-binding lectin polymorphisms and susceptibility to infection in systemic lupus erythematosus. Arthritis Rheum 1999;42:2145-2152.

20. Jacobsen S, Madsen HO, Klarlund M, Jensen T, et al. The influence of mannose binding lectin polymorphisms on disease outcome in early polyarthritis. TIRA Group. J Rheumatol 2001;28:935-942.

21. Ohlenschlaeger T, Garred P, Madsen HO, Jacobsen S, et al. Mannose-binding lectin variant alleles and the risk of arterial thrombosis in systemic lupus erythematosus. N Engl J Med 2004;351:260-267.

22. Schmiegelow K, Garred P, Lausen B, Andreassen B, et al. Increased frequency of mannose-binding lectin insufficiency among children with acute lymphoblastic leukemia. Blood 2002;100:3757-3760 


\section{Bodamer et al.}

23. Garred P, Larsen F, Madsen HO, Koch C, et al. Mannose-binding lectin deficiencyrevisited. Mol Immunol 2003;40:73-84.

24. Madsen HO, Garred P, Thiel S, Kurtzhals JA, et al. Interplay between promoter and structural gene variants control basal serum level of mannan-binding protein. J Immunol 1995;155:3013-3020.

25. Sumiya M, Super M, Tabona P, Levinsky RJ, et al. Molecular basis of opsonic defect in immunodeficient children. Lancet 1991;337:1569-1570.

26. Lipscombe RJ, Sumiya M, Hill AV, Lau YL, et al. High frequencies in African and non-African populations of independent mutations in the mannose binding protein gene. Hum Mol Genet 1992;1:709-715.

27. Madsen HO, Garred P, Kurtzhals JA, Lamm LU, et al. A new frequent allele is the missing link in the structural polymorphism of the human mannan-binding protein. Immunogenetics 1994;40:37-44.

28. Krawczak M, Ball EV, Fenton I, Stenson PD, et al. Human gene mutation database-a biomedical information and research resource. Hum Mutat 2000;15:45-51.

29. Stenson PD, Ball EV, Mort M, Phillips AD, et al. Human Gene Mutation Database (HGMD): 2003 update. Hum Mutat 2003;21:577-581.

30. Rozen S, Skaletsky HJ. Primer3 on the WWW for general users and for biologist programmers. In: Krawetz S, Misener S (eds) Bioinformatics Methods and Protocols: Methods in Molecular Biology. Humana Press, Totowa, 2000 pp 365386.
31. Mitterer G, Bodamer OA, Harwanegg C, Maurer W, et al. Microarray-Based Detection of Mannose-Binding Lectin 2 (MBL2) Polymorphisms in a Routine Clinical Setting. Genetic Testing 2005;9:6-13.

32. Huber M, Mundlein A, Dornstauder E, Schneeberger C, et al. Accessing single nucleotide polymorphisms in genomic DNA by direct multiplex polymerase chain reaction amplification on oligonucleotide microarrays. Anal Biochem 2002;303:25-33.

33. Huber M, Harwanegg C, Mueller MW, Schmidt WM, et al. On-Chip PCR: DNA Amplification and Analysis on Oligonucleotide Microarrays. In: Demidov VV, Broude NE (eds) DNA Amplification: Current Technologies and Applications. Horizon Bioscience, Wymondham, 2004; pp 77-95.

34. Su AI, Cooke MP, Ching KA, Hakak Y, et al. Large-scale analysis of the human and mouse transcriptomes. Proc Natl Acad Sci U S A 2002;99:4465-4470.

35. Bernig T, Taylor JG, Foster CB, Staats B, et al. Sequence analysis of the mannosebinding lectin (MBL2) gene reveals a high degree of heterozygosity with evidence of selection. Genes Immun 2004;5:461-476.

36. Skalnikova H, Freiberger T, Chumchalova J, Grombirikova H, et al. Cost-effective genotyping of human MBL2 gene mutations using multiplex PCR. J Immunol Methods 2004;295:139-147.

37. Park KS, Min K, Nam JH, Bang D, et al. Association of HYPA haplotype in the mannose-binding lectin gene-2 with Behcet's disease. Tissue Antigens 2005;65:260265. 